\title{
CUIDAR DO IDOSO DOENTE NO DOMICÍLIO NA VOZ DE CUIDADORES FAMILIARES ${ }^{1}$
}

\author{
TAKING CARE OF THE SICK ELDER PEOPLE AT HOME IN THE SPEECH OF FAMILIAL CARE TAKER
}

\author{
CUIDAR DEL ANCIANO ENFERMO EN EL DOMICILIO EN LA VOZ DE LOS CUIDADORES FAMILIARES
}

\author{
Roceli Brum Cattani ${ }^{2}$ \\ Nara Marilene Oliveira Girardon-Perlini ${ }^{3}$
}

\begin{abstract}
RESUMO : Esta investigação trata-se de um estudo exploratório, descritivo, numa abordagem qualitativa, que teve como objetivo conhecer como se dá a escolha do cuidador familiar de idoso doente e dependente no domicílio, e como o cuidador se sente neste papel. Através de visitas domiciliares, entrevistou-se o cuidador principal. A amostra constitui-se de nove cuidadores familiares, predominando mulheres: esposas, filhas, nora e neta, e marido. Para a análise dos dados utilizou-se a análise de conteúdo, seguindo os passos metodológicos de Minayo. Foram elaboradas duas categorias analíticas: ser cuidador familiar: uma opção ou uma obrigação?, a qual aponta que a escolha de cuidar está diretamente relacionada ao sentimento de obrigação, mas também às relações afetivas, à gratidão e à impossibilidade de optar por outro cuidador, e sendo cuidador familiar de idoso doente no domicílio, que aborda sentimentos do cuidador: a gratidão, a resignação; a inexperiência frente à demanda de cuidados; o cansaço físico e emocional; a perda de liberdade e a solidão da atividade.
\end{abstract}

PALVRAS-CHAVE : Família; Cuidador Familiar; Idoso; Dependência.

ABSTRACT: This investigation is about an exploratory, descriptive and in a qualitative approach study, which had as its objective to know how the choice of the sick elderly people's familial caretaker occurs and how the caretaker feels in this role. The main caretaker was interviewed in home visits. The sample was constituted of nine familial caretakers, mainly from the female sex: wives, daughters, daughters-in-law, granddaughters, and the husband. For the analysis of the data, the content analysis, following the methodological steps of Minayo, was used. Two analytical categories were elaborated: being a familial caretaker: is it an option or an obligation?, which shows that the choice of taking care is closely related to the feeling of obligation, but also to affection relations, gratitude and the impossibility of choosing another caretaker, and being a sick elderly people's familial caretaker that approaches feelings of gratitude, resignation, inexperience in face of the care demands, physical and emotional tiredness, loss of freedom and solitude due to the activity in the caretaker.

KEYWORDS : Family; Familial Caretaker; Elderly; Dependence.

RESUMEN : Esta investigación se trata de un estudio exploratorio, descriptivo, con un abordaje cualitativo, que tuvo como objetivo conocer el modo adoptado para la elección del cuidador familiar del anciano enfermo y dependiente en el domicilio, además de cómo el cuidador se siente desarrollando esta función. A través de visitas domiciliarias se entrevistó el cuidador principal. La muestra se constituye de nueve cuidadores familiares, prevaleciendo las mujeres: esposas, hijas, nuera y nieta, y marido. Para el análisis de los datos se ha utilizado el análisis del contenido, siguiendo los pasos metodológicos de Minayo. Han sido elaboradas dos categorias analíticas: ser cuidador familiar: ¿una opción o una obligación?, la cual señala que el escogimiento de cuidar está directamente relacionado al sentimiento de exigencia moral, pero también a las relaciones afectivas, como la gratitud y también la imposibilidad de optar por otro cuidador; $y$, siendo cuidador familiar de anciano enfermo en el

\footnotetext{
${ }^{1}$ Artigo elaborado a partir do Trabalho de Conclusão do Curso de Enfermagem apresentado à Universidade Regional do Noroeste do Estado do Rio Grande do Sul - UNIJUI em 2003.

2 Enfermeira. Hospital de Soledade. Soledade, Rio Grande do Sul.

${ }^{3}$ Enfermeira. Mestre em Enfermagem. Docente do Departamento de Ciências da Saúde da UNIJUÍ. E-mail: nara.girardon@unijui.tche.br
} 
domicilio, donde se presentan los sentimientos del cuidador: la gratitud, la resignación, la inexperiencia a la demanda de cuidados, el cansancio físico y emocional, la perdida de libertad y la soledad de la actividad.

PALABRAS CLAVES : Família; Cuidador Familiar; Anciano; Dependencia.

\section{INTRODUÇÃO}

O domicilio é visto hoje como um espaço em que pessoas portadoras de doenças crônicas e outras afecções, idosas ou não, podem viver com boa qualidade de vida e manter a estabilidade da doença. Assim, a experiência de cuidar de um doente em casa tem se tornado cada vez mais freqüente no cotidiano das famílias (GIRARDON-PERLINI, 2001). Em consonância a esta tendência, as políticas de atenção ao idoso defendem que o domicilio constitui-se no melhor local para o idoso envelhecer, sendo que permanecer junto à família representa a possibilidade de garantir a autonomia e preservar sua identidade e dignidade. Cuidar de idosos dependentes acometidos por uma patologia crônica ou aguda constitui-se então, numa situação freqüente para muitas famílias. Participantes ativos do cuidado, os cuidadores familiares ${ }^{4}$ desempenham atividades voltadas a suprir as demandas de acordo com as necessidades dos idosos doentes no próprio local onde residem.

Numericamente os idosos têm aumentado significativamente nos últimos anos, pois a velhice é uma etapa do ciclo da vida, que uma parcela crescente da população brasileira vem alcançando e desfrutando por mais tempo, em virtude do aumento da expectativa de vida e do acelerado envelhecimento populacional do país nas últimas décadas. Esta mudança no perfil demográfico, iniciada na segunda metade dos anos 70, quando houve um declínio da taxa de natalidade, aponta que para o ano de 2025 existirá, no Brasil, aproximadamente 30 milhões de idosos, que representarão $15 \%$ da população total (BRITO \& RAMOS, 1996).

Tal fato tem despertado a atenção para os problemas enfrentados pelos idosos e

\footnotetext{
${ }^{4}$ Cuidador familiar, neste estudo, é o termo que define a pessoa que por vínculos parentais assume a responsabilidade, direta ou não, pelo cuidado de um familiar doente e/ou dependente.
}

mostrando a necessidade de se garantir condições que propiciem envelhecimento com dignidade (CALDAS, 1998). A Secretaria Nacional dos Direitos Humanos considera, por lei, que idoso é a pessoa maior de sessenta anos sendo que "a família, a sociedade e o Estado têm o dever de assegurar ao idoso todos os direitos da cidadania, garantindo sua participação na comunidade, defendendo sua dignidade, bem estar e o direito à vida" (BRASIL, 1998, p.11).

Apesar dos esforços despendidos para garantir uma velhice cada vez mais ativa e saudável, a maioria dos idosos experimenta alguma fragilidade nessa fase. A doença traz consigo um fator emocional de regressão, no sentido de acentuar sentimentos de fragilidade, de dependência, de insegurança. O estado de doença acarreta algumas repercussões psíquicas inevitáveis, como preocupações, angústias, medos, alterações na auto-imagem e algum nível de dependência (DIOGO \& DUARTE, 2002).

Embora possuam diversos significados em meio a tantas culturas ou mesmo indivíduos distintos, num sentido mais geral, dependência segundo BALTES \& SILVERBERG, (1995), significa um estado em que a pessoa é incapaz de existir de maneira satisfatória sem a ajuda de outrem e autonomia, a capacidade do indivíduo em manter seu poder de decisão.

Sobre dependência LEITE (1995) diz que esta significa uma condição do idoso a qual se caracteriza por degenerescência decorrente de doenças crônicas ou de outras patologias, que the ameaçam a integridade física, social e econômica, diminuindo ou impedindo a capacidade do indivíduo para atender suas necessidades.

Dentre as alterações que conduzem o idoso a dependência destaca-se aquelas relacionadas ao adoecimento, as quais por suas características de cronicidade geram situações que necessitam da presença de outrem por longos períodos, sendo, nestas ocasiões, a família a principal fonte de 
cuidados. É nessa hora que os membros da família costumam assumir o papel de cuidadores, por terem uma responsabilidade culturalmente definida ou vínculo afetivo.

Ao falar em família, logo se pensa nas pessoas que têm laços parentais sanguíneos, como pais, mães, filhos, irmãos e primos, nos olvidando que outras pessoas também podem manter laços familiares, pois, além de estarem introduzidas nela, possuem vínculos entre si. A esfera familiar é uma unidade formada de seres humanos ao longo de sua trajetória de vida, cuidando de si próprio e de outros, sendo que as maneiras de cuidar variam de acordo com os padrões culturais e se relacionam com as necessidades de cada indivíduo (SARTI, 1993).

A família vai ser a concretização de uma forma de viver os fatos básicos da vida, se relacionando com o parentesco, mas não se confundindo com ele. O parentesco é uma estrutura formal que resulta de relações de consangüinidade entre irmãos; da relação de descendência entre pai e filho e mãe e filho; e da relação de afinidade que se dá através do casamento. Esta é uma estrutura universal, e qualquer sociedade humana se forma pela combinação destas relações (SARTI, 1993).

A saúde e a vulnerabilidade que a família possui são, de acordo com ELSEN et al. (2002), os dois elementos que dinamizam a estruturação deste sistema de cuidados, que demanda a participação de cada um de seus membros, não só para construí-lo, mas também para consolidá-lo e manter sua vigência. Ao ser cotidiana e coletiva esta construção requer solidariedade e ética da parte dos membros do grupo familiar.

Neste contexto o domicílio constitui-se no local onde os indivíduos desempenham suas atividades, formam laços de amor e ódio, interagem uns com os outros, têm seus momentos de lazer e algumas vezes, conforme as circunstâncias vividas, tornamse cuidadores de seus familiares, quando alguém adoece ou necessita de ajuda.

A atividade do cuidar de um familiar idoso doente e dependente no domicílio dáse no espaço onde parte significativa da vida é vivida, no qual o conhecimento e a memória de fatos e de relações íntimas são importantes tanto para o cuidador como para quem é cuidado. Neste ambiente, segundo KARSCH (1998), os cuidados têm suas peculiaridades. São regulados por relações subjetivas e afetivas, construídas numa história comum e pessoal. Os cuidados implementados pela família têm a finalidade de preservar a vida de seus membros para alcançar o desenvolvimento pleno de suas potencialidades, de acordo com suas próprias possibilidades e as condições do meio onde ela vive (ELSEN et al. 2002).

Geralmente a função de cuidador é assumida por uma única pessoa, denominada cuidador principal, seja por instinto, vontade, disponibilidade ou capacidade (MENEZES, 1994). Este assume tarefas de cuidado atendendo às necessidades do idoso e responsabilizandose por elas. Outro fator determinante para o familiar tornar-se cuidador, segundo KARSCH (1998) é a obrigação e/ou dever que o mesmo tem para com o idoso. Isto pode ser entendido como um sentimento natural e subjetivo ligado a um compromisso que foi sendo construído ao longo da convivência familiar.

MENDES (1995) explica que o processo de tornar-se cuidador pode ser mais imediato ou gradual. As decisões para assumir os cuidados são mais ou menos conscientes e, de fato, o que as pesquisas revelam é que, embora a designação do cuidador seja informal e decorrente de uma dinâmica específica, o processo parece obedecer a certas regras refletidas em quatro fatores que estão relacionados com o "parentesco, com freqüência maior para os cônjuges, antecedendo sempre a presença de algum filho; o gênero, com predominância para a mulher; a proximidade física, considerando quem vive com a pessoa que requer os cuidados e a proximidade afetiva,destacando a relação conjugal e a relação entre pais e filhos".

Os cuidadores atribuem sua vontade e seu compromisso à solidariedade com o companheiro (a) de vida, ao desejo de retribuir os cuidados recebidos na infância, ao seu horror ao asilamento e à ausência de outras alternativas (KARSCH, 1998). 
Para desenvolver seu processo de viver, conforme ELSEN et al. (2002), a família gera seu próprio sistema de cuidados, no qual estão refletidos seus saberes sobre a saúde e a enfermidade, impregnados de valores e crenças que se vão estruturando em seu cotidiano. Desta forma a participação de cada um de seus integrantes, os quais, a partir de suas próprias vivências, possibilidades e necessidades, vão desenvolvendo-se, fortalecendo-se e dinamizando-se, segundo o momento histórico em que se encontram.

Quando Souza apud DELGADO (2002, p.450) analisa a família que tem um integrante doente e suas formas de cuidado, refere que "cada um se cuida e cuida do outro" explicitando através desta constatação que "a família tem seus próprios recursos e sua capacidade de organização para cuidar de si quando tem um integrante doente“.

Neste sentido, o presente estudo tem por objetivo:

- conhecer como ocorre a escolha do cuidador familiar que irá cuidar de idoso doente no domicílio;

- descrever como os cuidadores familiares se sentem no processo de cuidar.

\section{PERCURSO METODOLÓGICO}

O estudo ora apresentado é de natureza qualitativa numa abordagem descritiva. CHIZZOTTI (1991) diz que na abordagem qualitativa há uma relação dinâmica entre o mundo real e o sujeito, uma dependência viva entre o sujeito e o objeto, um vínculo entre o mundo objetivo e a subjetividade do sujeito. O estudo descritivo busca descrever características de determinada população ou fenômeno (GIL, 1995).

Optamos por este tipo de pesquisa por considerarmos que o objeto em estudo busca, através da subjetividade dos cuidadores familiares, descrever como se dá a escolha do cuidador familiar e como estes como se sentem ao assumir a responsabilidade e prestar cuidados a um idoso doente em casa, apreendendo os significados expressos pelos mesmos.
O estudo foi realizado no município de ljuí (RS), o qual está situado na região do noroeste do estado, possui uma população de 78,461 habitantes e cuja atividade econômica baseia-se principalmente na prestação de serviços, na indústria e na agropecuária (IBGE, 2000) ${ }^{5}$.

Os sujeitos deste estudo foram cuidadores familiares principais de idosos acometidos por patologia crônica ou aguda que gerasse dependência parcial ou total e que estivessem sendo cuidados em seus domicílios. Consideramos dependência total quando o idoso dependia totalmente do cuidador para atender suas necessidades e como dependência parcial quando necessitava de ajuda para alguns cuidados ou atividades.

Para definirmos os sujeitos que comporiam a amostra elencamos, como critérios de inclusão, que os cuidadores familiares deveriam ser o cuidador principal e morar no domicílio com o idoso; estar prestando cuidados diretos ao idoso e que aceitassem participar da pesquisa. O tipo de dependência não foi considerado como elemento de análise.

Para definição do número de sujeitos a serem entrevistados utilizamos o critério da "saturação ou recorrência dos dados, ou seja, o momento em que a busca de novos sujeitos não acrescenta mais nenhum dado novo aa investigação" (VICTORA, et al., 2000, p. 51). Conforme MINAYO (1993, p. 102), em pesquisa qualitativa a representatividade amostral não é numérica, ou seja, "uma amostra ideal é aquela capaz de refletir a totalidade nas suas múltiplas dimensões, privilegiando os sujeitos sociais que detém os atributos que 0 investigador pretende conhecer [...]".

Assim, foram entrevistados nove cuidadores familiares, sendo seis do sexo feminino e três do sexo masculino, com idades entre vinte a setenta e três anos. As relações de parentesco com os idosos doentes formaram um grupo distinto, em que os entrevistados foram uma filha, um filho,

\footnotetext{
${ }^{5}$ http:// www1.ibge.gov.br/cidadesat/default. Php - Acesso em 21 de junho de 2003.
} 
três esposas, dois esposos, uma neta e uma nora. A profissão dos cuidadores foi: dois aposentados, um carpinteiro, uma estudante de ensino médio e cinco donas de casa. $O$ tempo em que desempenhavam a atividade de cuidar no domicílio foi de quatro meses a dez anos.

No que diz respeito aos idosos doentes e dependentes, seis era do sexo feminino e três do sexo masculino, de idades entre sessenta e seis anos a cento e dois anos, dos quais quatro idosos possuíam dependência parcial e cinco, dependência total.

Para localizar os sujeitos do estudo solicitamos indicações de professores supervisores de atividades práticas do curso de enfermagem da UNIJUÍ que atuavam nos bairros de abrangência de duas Unidades Básicas de Atenção à Saúde. Após as indicações foram realizadas visitas domiciliárias, para convidar os que contemplavam os critérios a participar e agendar as entrevistas. Algumas destas entrevistas foram realizadas já na primeira visita ao domicílio.

Os dados foram coletados nos meses de maio e junho de 2003, utilizando-se como instrumento a entrevista semi-estruturada, contendo questões referentes aos dados pessoais dos idosos doentes e dos cuidadores e duas questões abertas (Conteme como você começou a cuidar do seu "fulano"? Fale-me como você se sente cuidando do seu "fulano"?), que foi gravada em audiotape e posteriormente transcritas na íntegra.

Como método de análise dos dados, utilizamos a análise de conteúdo que, para CHIZZOTTI (1991) visa compreender criticamente o sentido das comunicações, seu conteúdo manifesto ou latente, as significações explícitas ou ocultas. A técnica de análise seguida deu-se conforme as fases de análise de MINAYO (2001) e, seguindo a sua proposta, os passos foram: ordenação dos dados, classificação dos dados e análise final.

Consideramos importante destacar que a mesma autora retrata, a título de conclusão, que o produto final da análise de uma pesquisa, por mais brilhante que seja, deve ser sempre encarado de forma provisória e aproximativa.

Em atenção a Portaria 196/96 do Conselho Nacional de Saúde do Ministério da Saúde que normatiza a pesquisa envolvendo seres humanos, inicialmente, nas visitas domiciliárias, foi explicado os objetivos do estudo, convidando, então, os cuidadores familiares a participar da entrevista, garantindo os aspectos éticos previstos neste documento (BRASIL, 1996).

Todos os convidados aceitaram participar do estudo e assinaram o Termo de Consentimento Livre e Informado sendo que uma via permaneceu com o entrevistado e a outra com a pesquisadora. Salientamos, todavia, que o projeto de pesquisa não foi submetido à apreciação de um Comitê de Ética em Pesquisa, porque a instituição à qual está vinculado, não dispunha, naquele momento, este órgão em funcionamento.

Como forma de preservar o anonimato e identificar os sujeitos da pesquisa, considerando que a realidade os torna detentores de "poderes mágicos" para assumir várias formas de ser e de estar no cotidiano do cuidado com o outro (familiar doente e dependente), de si mesmos e das demandas familiares, optamos por nominálos com nomes de super-heróis.

\section{APRESENTAÇÃO E A ANÁLISE DOS DADOS}

Ao realizar este estudo buscamos conhecer com se dá a escolha do familiar que irá cuidar do idoso doente no domicílio e como estes se sentem no processo de cuidar, afim de que se possa compreender um pouco mais acerca desta realidade. Os dados coletados permitiram a organização de duas categorias de análise que foram elaboradas a partir do conteúdo das entrevistas, por convergência de idéias. Ser cuidador familiar: uma opção ou uma obrigação? e Sendo cuidador familiar de idoso doente no domicílio que aborda sentimentos do cuidador: da gratidão a resignação; sentindose inexperiente frente à demanda de cuidados; sentindo cansaço físico e 
CATTANI, Roceli Brum; GIRARDON-PERLINI, Nara Marilene Oliveira - Cuidar do idoso doente no 259 domicílio na voz de cuidadores familiares. Revista Eletrônica de Enfermagem, v. 06, n. 02, p. 254-271, 2004. Disponível em www.fen.ufg.br

emocional; cuidar sentindo perda de liberdade e sendo solitário.

\section{Categoria 1. Ser cuidador familiar: uma opção ou uma obrigação?}

Definir quem será o cuidador familiar de um idoso doente no domicílio constitui-se numa situação em que a família, na maioria das vezes, necessita reorganizar-se e negociar possibilidades, que incluem identificar, conforme o parentesco, a disponibilidade de tempo e o desejo pessoal, quem poderá assumir essa tarefa.

A partir das informações obtidas junto aos colaboradores deste estudo percebemos que o grau de parentesco tem influência decisiva na escolha de quem irá cuidar, ou seja, quanto mais próxima for a relação familiar, mais chances tem esta pessoa de vir a ser a responsável pelo cuidado do idoso, conforme descrito na literatura.

Alguns entrevistados referiram que assumiram o cuidado do idoso doente porque entendem ser uma obrigação matrimonial, tanto de esposo como de esposa, pois uma vez casados constitui-se em dever um cuidar do outro até o fim da vida. Atribuem esta responsabilidade ao acordo firmado perante Deus, por ocasião do matrimônio, em que se comprometeram a partilhar alegrias $e$ tristezas, além de estarem juntos na saúde e na doença, conforme pode ser evidenciado nas seguintes manifestações:

"A senhora sabe que antigamente a gente, tendo, casado, fez aquele juramento pra Deus e as coisas assim, nas horas boas e nas horas ruins, a gente tem que estar sempre junto, pra cuidar, eu tenho que cuidar, o que eu vou fazer, abandonar não dá"." (Heman)

Esta obrigação também é mencionada por aqueles que tem uma vida em comum, que mesmo não tendo formalizado a sua união de acordo com um ritual religioso ou num contrato civil, sentem-se com o mesmo tipo de responsabilidade.

\begin{abstract}
"Penso assim que, que eu tenho que cuidar dele, porque estou junto com ele. É meu companheiro, então tenho que cuidar". (Shenna)
\end{abstract}

Em investigação realizada por SILVA (1995) na qual buscou conhecer as relações de gênero e poder entre cuidadoras mulheres e pacientes acometidos por Acidente Vascular Cerebral (AVC) e que perderam sua independência, constatou que para algumas cuidadoras a "opção" de cuidar é vista como uma obrigação que está embutida no seu papel de esposa, estando relacionado ao projeto de vida do casal, já que o casamento se constitui em um projeto de vida comum que inclui a questão do cuidado pelo outro.

Associado ao fato de cuidar como uma função inerente ao casamento, evidencia-se que também existe um componente afetivo que conduz essa atuação e contribui para que um cônjuge cuide do outro: o sentimento de carinho, de gostar do outro, como pode ser percebido nesta fala:

"Mas porque, é meu esposo, a gente cuida, é uma pessoa que a gente quer bem, a gente cuida nem que não seja esposa, que seja mãe, cuida, Não há como um porque, não há uma obrigação eu acho, e sim gostar da pessoa. Eu acho que, que mais que obrigação é um dever que a gente tem, um cuidar do outro, tem que ser, quando não der mais, terá que se arrumar uma pessoa mais". (Sherra)

O cuidar se apresenta como uma manifestação de afeto, pois como diria o poeta, "quem ama, cuida", e a concepção popular de amar remete a essa forma de compromisso com $\mathrm{O}$ outro. $\mathrm{Na}$ língua portuguesa cuidar denota "aplicar a atenção; o pensamento; ter cuidado com os outros e consigo mesmo; tratar de assistir", dentre outros sinônimos (FERREIRA, 1999, p. 589).

Embora a cuidadora refira-se ao afeto como motivação para cuidar, evidencia-se que cuidar de seu esposo também é um dever, mais que uma obrigação, podendo se 
CATTANI, Roceli Brum; GIRARDON-PERLINI, Nara Marilene Oliveira - Cuidar do idoso doente no 260 domicílio na voz de cuidadores familiares. Revista Eletrônica de Enfermagem, v. 06, n. 02, p. 254-271, 2004. Disponível em www.fen.ufg.br

notar o expressivo traço cultural, no qual sendo esposo, tem que ficar junto e dedicarse na realização dos cuidados. Assim, podemos depreender que o componente afetivo apresenta-se como um fator importante e influencia na escolha do cuidador, porém este estará acompanhado de valores impostos pela cultura familiar, ou seja, os direitos, deveres e obrigações dos membros da família.

Dever é definido como se ter obrigação ou necessidade de; ser devedor de; aquilo a que se está obrigado por lei, pela moral, pelos costumes, incumbência ou obrigação; sendo que obrigação é definida como dever; imposição; tarefa necessária; compromisso; motivo de reconhecimento; favor; serviço; preceito...(FERREIRA, 1999). Assim, quando o cuidador se refere a seu dever ou a sua obrigação, podemos considerar que este está se referindo a uma obrigação moral determinada, expressa em uma regra de ação, que nesse caso é o cuidar.

Culturalmente, a sociedade espera essa atitude dos casais e, segundo $\mathrm{KARSCH}$ (1998), para cuidadoras esposas, o ato de cuidar está embutido no seu papel de mulher casada, a partir do compromisso assumido e selado desde o momento do matrimônio. Este compromisso associa-se a valores como responsabilidade e obrigação e o dever como um sentimento natural e subjetivo. Cuidar do companheiro, enquanto puder, enquanto tiver forças, tem uma representação para os cuidadores, no sentido de ser valorizado e reconhecido pelas outras pessoas, por aquilo que faz. De certo modo, há um heroísmo que os torna respeitados perante a sua comunidade, pois estão cumprindo com suas obrigações.

Nesse sentido, SOMMERHALDER \& NERI (2001) em uma investigação com 15 mulheres cuidadoras principais de idosos de alta dependência identificaram que os benefícios relatados por estas estavam relacionados a crescimento pessoal, senso de auto-realização, senso de significado e senso de reciprocidade. No aspecto social os ganhos relacionaram-se à valorização social, à satisfação pelo cumprimento de normas sociais e benefícios às relações familiares.
Também MENDES (1995) reforça a idéia de que os cuidadores entendem a atividade de cuidar como um dever moral decorrente das relações pessoais e familiares inscritas na esfera doméstica, visto que muitos cuidadores não se viam como tais e, a partir do momento que necessitam desempenhar tal papel, o assumem como uma exigência decorrente do viver em família.

O dever, entretanto, refere-se a ações impostas por normas sociais. Estas por sua vez, estão inscritas num conjunto de crenças e valores compartilhados entre membros de uma sociedade, sendo que a família é o lugar da transmissão, introjeção e manutenção dos valores.

Para os casais, principalmente, os idosos, cuidar de seu companheiro(a) é tido como uma etapa normal e esperada no processo de envelhecer o que, como diz MENDES (1995), faz, muitas vezes, com que "o cuidador de um idoso doente e dependente seja outro idoso, que por sua vez também pode ter restrições em sua saúde, porém, encontra-se em melhores condições, o que os possibilita cuidar".

Quando o cônjuge não pode desempenhar esse papel ou já é falecido, a responsabilidade pelos cuidados passa a ser uma obrigação filial. Os filhos referem que cuidam porque não há outra alternativa, pois "mãe é mãe". O sentimento para com o idoso é fortuito, cuidam pelo amor que sentem pelo genitor, procurando aceitar seus defeitos, e pelos laços de afeto que os une.

"Olha eu, eu faço, porque isso tem que fazer, ela é minha mãe, tudo, o que eu vou fazer, tem que fazer igual e (...) suportar o que a mãe é". (Superhomem)

Quando os idosos precisam de ajuda, os filhos adultos costumam assumir o papel de cuidadores, por terem um vínculo afetivo e uma responsabilidade culturalmente definida, conhecida como "obrigação filial" (Bleiszner, apud PAVARINI et al., 2001).

Ser cuidador da própria mãe (ou pai) transcende $\mathrm{o}$ ato em si, pois resgata 0 
CATTANI, Roceli Brum; GIRARDON-PERLINI, Nara Marilene Oliveira - Cuidar do idoso doente no 261 domicílio na voz de cuidadores familiares. Revista Eletrônica de Enfermagem, v. 06, n. 02, p. 254-271, 2004. Disponível em www.fen.ufg.br

carinho, o amor, as desavenças do cotidiano e possibilita a retribuição de valores, de cuidados e também, de certa forma, o fato de existirem.

"Eu (filha) tenho amor por ela, à gente se não fosse ela, a gente não estava no mundo". (Mulher Maravilha)

"É eu cuido, é minha mãe, tenho carinho por ela. É o que eu posso fazer hoje por ela, é cuidar". (Super-homem)

Mesmo que esta obrigação seja vista como um fator inerente à condição de filhos, outras figuras se apresentam neste estudo como cuidadoras. A neta, embora não seja filha, sente-se como tal e, portanto, imbui-se da mesma obrigação filial. Ao residir com a avó, passou a cuidá-la diariamente, sentindose responsável por ela. Além disso, separada dos pais, por motivos familiares, relata que com o passar do tempo, do carinho e da atenção da avó a considera como a própria mãe.

"Se eu fosse escolher eu não ia
escolher cuidar dela, aí então como
surgiu eu cuidar dela, eu aceitei. Daí
fosse uma escolha assim, no meu ver,
antes eu não ia querer cuidar de uma
pessoa idosa doente, mas surgiu a
oportunidade, então eu vim cuidar.
Também ficou na minha
responsabilidade e eu fiquei aqui
então. E eu tenho um carinho de mãe
com ela, o carinho que a minha mãe
não teve por mim ela teve". (Bat girl)

A responsabilidade que the foi imposta frente às circunstâncias familiares sem possibilidade de optar ou não por tal tarefa, fez com que o cotidiano fosse moldando a relação familiar e a realização dos cuidados para com a idosa doente, na esfera familiar. Tornar-se cuidador de um familiar idoso e dependente no domicílio implica em alguns fatores que levam o cuidador a assumir-se como tal, como, por exemplo, ser o familiar mais próximo e do fato dos outros se desvencilharem do cuidado.
Também, como cuidadora identifica-se à nora, que cuida da mãe de seu esposo. Ambos residem no mesmo domicílio e, como nestas ocasiões, em que alguém necessita de cuidados no âmbito familiar, alguém tem de executar, a nora, devido às contingências, assumiu esta tarefa. Considerando que o cuidado é culturalmente desempenhado pela figura feminina, a nora o realiza, pois o filho precisa trabalhar e considera esta uma tarefa a ser desempenhada pela mulher. Refere também que realiza um sistema de rodízio com uma das filhas da idosa, quando uma ou outra precisa viajar, porém ainda fala que os outros filhos se desvencilharam do cuidado, então alguém precisa realizá-los.

"Vou cuidar dela até quando ela precisar de mim, enquanto eu puder, eu cuido. Por isso que enquanto eu puder e tiver saúde eu cuido dela, agora o dia que eu não puder mais, daí as filhas vão ter que assumir ela daí. Por enquanto sou eu que estou assumindo e vou assumir até enquanto der, pra cuidar dela. Gosto dela, quero bem e tudo e os outros não querem, não tem muita vontade de cuidar, então alguém tem que cuidar". (Mulher Gato)

A colaboradora explicita que enquanto puder desenvolver os cuidados à sogra irá fazê-los, entretanto quando isto não for possível, enfatiza que as filhas é que deverão assumir os cuidados. De certa forma, sua mensagem deixa transparecer que na sua concepção esta função compete às filhas, e não a ela.

O assumir o fato de ser o responsável pelo cuidado não é uma opção, porque em geral, o cuidador não toma a decisão de cuidar, mas esta se define na indisponibilidade de outros possíveis cuidadores para cuidar e, quanto mais o cuidador se envolve, mais os não-cuidadores se desvencilham do cuidado (KARSCH, 1998). Assim percebemos que, uma vez assumindo, o cuidado dificilmente é transferível.

A aceitação de ser cuidador se dá, geralmente, num processo que pode ser 
CATTANI, Roceli Brum; GIRARDON-PERLINI, Nara Marilene Oliveira - Cuidar do idoso doente no 262 domicílio na voz de cuidadores familiares. Revista Eletrônica de Enfermagem, v. 06, n. 02, p. 254-271, 2004. Disponível em www.fen.ufg.br

explicado como uma forma de "impulso" inicial e ou de slipping into it (escorregar para dentro) conforme Ungerson (1987), Lewis \& Meredith (1988) apud MENDES (1995). Ou seja, em princípio, a pessoa, num ato espontâneo e impulsivo assume o cuidar ou, sem perceber, vai assumindo pequenos cuidados e quando percebe já é o cuidador principal, estando completamente comprometido. "É como se de um lado o cuidador escorregasse cada vez mais para dentro da situação e, de outro, os não cuidadores deslizassem cada vez mais para fora dela" (KARSCH, 1998, p.138).

\section{Categoria 2 : Sendo cuidador familiar de idoso doente no domicílio}

\section{Sentimentos do cuidador: da gratidão a resignação}

Desempenhar a tarefa de cuidar do idoso doente e dependente no domicílio deflagra diferentes sentimentos que são vivenciados pelos cuidadores diariamente. Alguns entrevistados relatam que para ser cuidador é imprescindível ter algumas qualidades, que os possibilitem resistir ao cotidiano. Têm que se conformar, "agüentar" cuidar do idoso, pois não há o que fazer. Segundo eles, qualquer atitude, como abandonar a função, brigar com o idoso e os outros familiares, não mudará a situação de ser cuidador, nem a situação do idoso doente, pois este continuará dependente e possivelmente não haja outra pessoa para assumir o cuidado. Assim, não podendo abdicar de tais responsabilidades, acabam sentindo-se impotentes diante da situação e a aceitam como imutável, resignando-se às circunstâncias.

"Em cuidar eu me sinto bem, fazer o quê, estou junto, tenho que cuida,r tenho que agüentar". (Shenna)

[...] Ele está doente, tenho que cuidar. Paciência. E se não tem paciência, e daí?"(Sherra)

Outra colaboradora ainda expressa a "raiva" como um sentimento passageiro, mas que se faz presente frente ao cuidar. Muitas vezes torna-se incomodada pela condição de ser cuidadora, de ter que cuidar de alguém doente, entretanto, afirma que o sentimento é temporário, efêmero e que com o passar do tempo, na medida do possível, tudo volta ao "normal".

"Me dava raiva assim, mas depois que a raiva passava, daí (...)". (Tempestade)

"Bem, às vezes tem umas resmunguinhas ou outra, mas ela não aceita, às vezes a gente briga por causa de remédio dela e outras coisas, mas é coisinha, assim". (Bat girl)

O cotidiano do cuidado favorece o surgimento de sentimentos de insatisfação por parte do cuidador e a manifestação do seu descontentamento, entre outros motivos, pode produzir situações de conflito entre ele e o familiar. Refletir sobre estes desencontros desencadeia sentimentos ambíguos para ambos os lados. Ao cuidador o sentimento de compaixão pela dependência do idoso e de desagrado pelas limitações que lhe impõe a condição de cuidador. Ao familiar que está sendo cuidado, a indignação pela dependência e o reconhecimento pela ajuda recebida. Conforme KARSCH (1998), o cuidador não pode ficar pensando nos problemas de relacionamento que poderão surgir no decorrer do cuidado, mas este deve fazer o que tem que ser feito, porque, ao ficar preocupado, não cuida e nem muda a situação.

Considerando as motivações que permeiam a tarefa de cuidar, evidencia-se no cuidado uma forma de agradecimento pelas experiências vividas e pelos cuidados e atenção recebidos no passado. A fala abaixo expressa esse sentimento.

"Então eu acho que chegou a vez de eu retribuir o que ela fez por mim". (Batman)

"Eu tenho carinho por ela, ela me deu amor. Então agora tenho que cuidar dela, retribuir pra ela". (Bat girl) 
CATTANI, Roceli Brum; GIRARDON-PERLINI, Nara Marilene Oliveira - Cuidar do idoso doente no 263 domicílio na voz de cuidadores familiares. Revista Eletrônica de Enfermagem, v. 06, n. 02, p. 254-271, 2004. Disponível em www.fen.ufg.br

Sentimentos de gratidão são perceptíveis, principalmente, nas relações em que os filhos são cuidadores dos pais. SILVA (1995) em sua pesquisa com cuidadoras de adultos dependentes, analisando a relação mães-filhas, conclui que as filhas ao assumirem os cuidados querem retribuir 0 que a mãe fez ao longo de suas vidas, especialmente no período em que dependiam dos pais para a sua manutenção. É como se fosse uma espécie de "retribuição" pelos esforços realizados pela mãe ao criá-las.

\section{Sentindo-se inexperiente frente à demanda de cuidados}

O exercício de cuidar do idoso doente no domicílio é um aprendizado constante, baseado nas necessidades físicas e biológicas e de acordo com o nível de dependência do idoso. Na maioria das vezes se torna difícil, pela inexperiência do cuidador, atender as demandas que vão surgindo no transcorrer do processo do cuidar e que necessitam ser aprendidas no enfrentamento do cotidiano.

Atividades que parecem ser simples, para quem já as desenvolve, se tornam árduas para quem nunca precisou enfrentálas. Assim, o cuidar, que inicialmente abrange atividades simples que se limitam a ajudar na realização de atividades da vida diária, como ajudar no vestir-se ou a servir de apoio para andar na rua, podem, gradativamente, ir se complexificando e exigindo do cuidador conhecimento e habilidades para o exercício do cuidar de acordo com as necessidades físicas do idoso.

"Daí, eu tive que aprender como dar banho nela em cima da cama, eu tive que aprender como trocar de roupa nela, os cuidados que tinha que ter pra não dar aquelas feridas no corpo dela, tudo eu tive que aprender". (Batman) "Eu tive que aprender a lidar com o oxigênio, com tudo, praticamente. Desde as pequenas coisas". (Sherra)

Com isso, o processo de tornar-se cuidador é gerado no enfrentamento diário, segundo Mendes (1995), aprendendo a lidar com as necessidades do idoso doente $e$ muitas vezes, tendo que se adaptar a elas. Também, nesse sentido, GIRARDONPERLINI (2001, p.118) em um estudo com cuidadores familiares principais de pessoas incapacitadas em decorrência de AVC que cuidam no domicílio, identificou que a maioria dos cuidadores referiu ter "aprendido a cuidar na prática do dia - a - dia , como um autodidata, fazendo, errando e acertando e, em segundo lugar, observando e auxiliando a enfermagem durante a internação, o que reflete também um aprender por si mesmo".

Os cuidadores descrevem que tiveram que incorporar e desenvolver a cada dia uma nova gama de cuidados, adequando-os às necessidades do idoso que, conforme a dependência, vai se apresentando no transcurso da evolução de sua doença, o que torna 0 cotidiano cansativo e repetitivo. Referem que as noites são mal dormidas, geradas pela preocupação em saber se o idoso está bem, pelo compromisso de administrar medicamentos nos horários corretos e pela repetição de tarefas.

"Em casa tenho que cuidar de noite e dia, durmo um sono e me acordo, pra ir lá atender ele, ver se tá coberto, tapado, dar um remédio (...). E é isso (...). Acordar, levantar, tratar de esquentar uma água". (Shena)

"Eu fui cuidando ele, conforme as necessidades dele e cada vez mais, eu tive que ir fazendo as coisas pra ele, até chegar um ponto assim, que agora eu que dou banho, eu que tenho que ajudar ele a pôr na cadeira, às vezes nem na cadeira não dá pra ir, tem que colocar fralda, então, e (...)". (Sherra)

Outros colaboradores mencionaram que iniciaram os cuidados conforme as necessidades que 0 idoso doente apresentava, porém, com o passar do tempo, a dependência do mesmo foi aumentando e a sobrecarga de cuidados também, posto às exigências da evolução da doença. Percebemos que os cuidadores sentem-se sobrecarregados pela demanda de cuidados 
e, também, por terem que realizar tarefas que até então eram atividades pessoais do idoso, realizadas por eles próprios, como tomar banho e ir ao banheiro e que agora, com o avanço da patologia, tem de ser executada pelo cuidador.

Ser cuidador de um idoso doente e dependente seja ele parcial ou total, no âmbito doméstico, como refere MENDES (1995), é uma atividade absorvente que preenche o dia, e às vezes, à noite da pessoa que assume cuidar deste familiar, pois 0 cotidiano é o espaço do imediato em que os indivíduos devem operar as atividades através do saber prático.

As mudanças que se instalam na nova dinâmica de vida do cuidador estão, principalmente, relacionadas a reacomodação das atividades, com reformulação de horários, preparação de uma alimentação, muitas vezes, diferenciada, administração de medicamentos, estabelecimento de uma rotina para exercícios e atividades de conforto que incluem efetuar a higiene pessoal, pentear 0 cabelo, escovar os dentes, cortar as unhas, fazer a toalete, vestir, despir, locomover de um lugar para outro, subir escadas, sentar, levantar, deitar, entre outras (MENDES, 1995; KARSCH, 1998).

Assim, ao cuidador familiar é apresentada a necessidade de incorporar a nova realidade ao seu cotidiano, muitas vezes árdua e desgastante, conforme o que o idoso doente apresenta, e conviver com ela.

\section{Sentindo cansaço físico e emocional}

Associado ao aprendizado constante do cuidar, posto o enfrentamento do cotidiano e a repetição de cuidados para com o idoso doente e dependente no âmbito domiciliar, surge, dentre os entrevistados, manifestações relacionados a cansaço físico e emocional.

Cansaço emocional, conforme FREITAS et al. (2002), se caracteriza pela perda progressiva de energia, fadiga e esgotamento emocional. Reflete a situação em que os trabalhadores não podem dar de si no âmbito afetivo. Trata-se de uma diminuição da energia vital, assim como dos recursos emocionais. É uma experiência de desgaste psicológico ocasionado pela assistência cotidiana prestada a usuários que demandam ajuda. Já o cansaço físico pode ser entendido como fraqueza causada por exercício ou doença e ainda por atividades que exige esforço físico, agregado a repetição das mesmas (FERREIRA, 1999).

O cuidar diariamente de alguém que apresenta dependência pode significar 0 desenvolvimento de atividades que envolvem esforço físico para a prestação de alguns cuidados e, também, estar atento à execução de determinados procedimentos que exigem concentração e planejamento antecipado do que será feito, afim da obtenção de resultados satisfatórios no cuidado que tem de ser realizado. Com o tempo vão surgindo características estressantes da atividade de cuidar, o desgaste físico e emocional dos cuidadores.

"Que, a cabeça da gente é muita coisa né. É a mesma coisa que a senhora tivesse cansada demais, bem cansada, a senhora não dorme direito e essa canseira na cabeça da gente que vem de certo, essa amoaceira, essa canseira e a gente fica assim".( Heman)

Como pode ser observado, as noites tornam-se mal dormidas e o acúmulo de preocupações, que envolvem a prática do cuidar, fazem com que o cuidador fique "amoado" e sentindo-se "fraco mentalmente", referindo-se ao cansaço emocional causado pelo estresse da responsabilidade de cuidar diariamente do idoso doente.

Postos às exigências do cuidar, os colaboradores deste estudo demonstraram que cuidar de um idoso doente no domicílio é uma tarefa cansativa, pois Ihes ocupa muito tempo. Além das atividades que envolvem o cuidado ao idoso doente no domicílio, aliamse a estes os afazeres domésticos que consomem outra parte do tempo, tendo, com isso, que organizar as ações de modo a conseguir dar conta da demanda de todos os trabalhos. 
"Canso, mas Deus o livre, estou cansada mesmo. A filha dele diz que está cansada e vai descansar, mas eu tenho que lavar roupa, limpar a casa, fazer a comida (...)". (Shena)

As atividades relacionadas ao lar, como aponta KARSCH (1998), estão inscritas nas necessidades de tarefas a serem desenvolvidas pelos cuidadores no dia-a-dia, sendo que isto imputa a eles uma jornada de trabalho que, muitas vezes, estende-se ao longo do dia e para a qual não contam com ajuda de outras pessoas. Conciliar as atividades domésticas com os cuidados pessoais e os cuidados ao idoso dependente exige habilidade na organização do tempo e da execução dos mesmos.

Analisando cuidadoras - mulheres de adultos acometidos por AVC, SILVA (1995) constatou que a maioria das cuidadoras admite que sua vida mudou radicalmente após assumir esse papel, pois além das tarefas caseiras aumentarem, 0 idoso normalmente precisa ser auxiliado nos cuidados pessoais. $O$ cansaço foi 0 sentimento mais comum entre as cuidadoras, e nos casos em que o paciente tinha incontinência urinária e/ou de fezes, essa situação era mais aguda, pois, na sua maioria, era somente a cuidadora que lidava com a troca de roupas.

Também se referindo aos afazeres dos cuidadores, FREITAS et al. (2002) menciona que estes percebem o cuidar como um trabalho solitário e gerador de sobrecarga, principalmente de natureza física, que se expressa em cansaço, insônia e problemas de saúde.

Percebe-se que em certas ocasiões os cuidadores se sentem esgotados, sem condições para cuidar, porém como o idoso não pode se autocuidar nem, muitas vezes, colaborar nos cuidados, o cuidador tem de fazer as atividades, superando as próprias dificuldades e limitações. Diante do desgaste pessoal e da dependência do outro, chega a se questionar se o familiar realmente não consegue cooperar nos cuidados, surgindo dai um certo conflito interno e de culpa por estar em dúvida quanto a dependência do outro. Esta constatação pode ser reforçada com a afirmação de FREITAS et al. (2002) de que cuidar não é uma situação linear em que são vivenciados sempre os mesmos sentimentos e por isso existem conflitos e ambivalências.

A gente diz que também não está, como é que a gente diz, assim, com muita vontade de fazer isso. Isso cansa, fico nervosa e até a gente não devia ficar, porque ele também não tem culpa, mas a gente pensa, será que ele está tanto assim que, não podia se ajudar um pouco". (Sherra)

Para SILVA (1995) o esgotamento físico e emocional relatado pelas cuidadoras, está associado a múltiplos fatores. Além das tarefas dos cuidados, sofrem pressão cotidiana decorrentes do próprio estado de saúde do doente, que gera a dependência física e emocional; da falta de ajuda de outros familiares; das dificuldades financeiras para a manutenção da própria família; da ausência de suporte formal por parte do Estado, como por exemplo, atendimento domiciliar médico, de enfermagem, de fisioterapia e medicamentos. Prestar cuidados a um idoso muitas vezes leva o cuidador a reestruturar sua vida, alterando costumes, rotinas, hábitos e até mesmo a natureza de sua relação com o idoso (NERI, 1993).

As exigências no cuidar, de acordo com FREITAS et al. (2002), parecem ser mais fortes no início de cada nova atividade, porém o senso de sobrecarga pode se estabilizar ou diminuir ao longo do tempo, em virtude de uma variedade de processos que ocorrem na vida do cuidador, tais como aprender a desempenhar as tarefas, reorganizar-se de acordo com suas disponibilidade e com as demandas ou estabelecer novos níveis de adaptação para comportamentos e estados psicológicos. Além disso, a evolução da doença pode ocasionar mudanças no curso das exigências.

Outro fator a contribuir no desgaste emocional dos cuidadores está relacionado 
CATTANI, Roceli Brum; GIRARDON-PERLINI, Nara Marilene Oliveira - Cuidar do idoso doente no 266 domicílio na voz de cuidadores familiares. Revista Eletrônica de Enfermagem, v. 06, n. 02, p. 254-271, 2004. Disponível em www.fen.ufg.br

às dificuldades financeiras. Diante da impossibilidade de suprir todas as necessidades que o familiar necessita e que a doença exige, se sentem impotentes e tristes.

"É, nessas condições, e de qualquer maneira, eu só me sinto triste às vezes, quando eu não posso alcançar o que ele precisa, que nem sempre eu posso fazer o que ele precisa, tanto financeiro como ... Mais o financeiro, que é difícil, porque ele, é uma doença que requer muito, só alimentação é muito cara e, às vezes tu tem dinheiro, às vezes não tem". (Tempestade)

"Quê, cuidar não é nada vizinha, pior são as dificuldades que a gente tem, por exemplo, pra comprar um remédio, as coisas financeiras e tal, paga isso, aquilo e a gente ganha pouco, dinheiro de aposentado já viu, é pouca coisa, duzentos pila, duzentos e poucos pila, então tudo isso vai acumulando, a gente vai indo". (He-man)

Quando comparam o ato de cuidar com os gastos para atender as necessidades dos idosos, ponderam que cuidar não é tão oneroso, pois o mais difícil é dar conta dos custos que a doença exige para suprir todas as carências do idoso. Como maioria dos participantes do estudo dependem dos valores recebidos como aposentados da previdência social, referem que 0 valor recebido pelos benefícios, às vezes, a única fonte de manutenção e sobrevivência, é insuficiente para atender as necessidades básicas do idoso doente e dependente.

Assim, diante das limitações financeiras, buscam, primeiramente, suprir as necessidades do idoso, pois os gastos com a doença são ordem prioritária sendo que os gastos domésticos e pessoais podem ser deixados em segundo plano.

\section{Cuidar sentindo a perda de liberdade e sendo solitário}

Os cuidadores deste estudo além de mencionar o cansaço físico e emocional como fatores desgastantes desencadeados durante 0 processo de cuidar referem, também, a necessidade de "abrir mão" de atividades que eram praticadas habitualmente, antes de se tornarem cuidadores familiares. Ser cuidador de um idoso doente na esfera domiciliar é, na maioria das vezes, ter que negligenciar sua própria vida ou parte dela. A prioridade, neste momento, é cuidar de seu familiar doente, realizar o que ele necessita abdicando de suas próprias vontades.

Um dos maiores obstáculos apontados enquanto vivenciam o processo de cuidar é a impossibilidade de sair de casa, passear, pois, de forma geral ficam atrelados à responsabilidade e a preocupação diária com a doença e cuidado do idoso. A pouca realização de atividades de lazer no cotidiano e a limitadas possibilidades de conversar com outras pessoas contribuem para o sentimento de solidão e de perda da liberdade.

"Não tenho liberdade, faz anos que eu já não tenho mais a liberdade pra sair, assim passear, a senhora pensa, bá, capaz, saía ali, já tinha que estar em casa de volta. Gente doente em casa é uma coisa ou outra, chega uma pessoa a gente sempre com aquele cuidado, aquela coisa, aquela aflição parece dentro da gente". (Heman)

"Minha vida é sofrida, porque a gente fica assim sem poder sair, tem que ficar em casa isolada e se eu saio um pouquinho ela está chamando, ela está procurando, se eu vou sair eu tenho que falar bem com ela, explicar bem pra ela o que eu vou fazer". (Mulher Maravilha)

Como diz MENDES (1995), existe uma dinâmica no processo de cuidar que é uma relação tensionada onde os sujeitos envolvidos, cuidador e idoso dependente, constroem seus espaços respectivos, dentro dos limites dessa nova relação pessoal. Desse modo, os cuidadores também apontam que a perda da liberdade se desencadeia pelo vínculo e pela dependência que o idoso manifesta, ou seja, quanto mais o 
CATTANI, Roceli Brum; GIRARDON-PERLINI, Nara Marilene Oliveira - Cuidar do idoso doente no 267 domicílio na voz de cuidadores familiares. Revista Eletrônica de Enfermagem, v. 06, n. 02, p. 254-271, 2004. Disponível em www.fen.ufg.br

doente necessita de cuidados ou se sente sozinho, mais o cuidador tende a ficar "isolado" no domicílio para cuidar deste.

Para cuidadoras de um estudo realizado por SILVA (1995), o sentir-se privado do contato nas relações com amigos e parentes é bastante visível, já que a possibilidade de sair de casa é cada vez mais escassa e as visitas são mais esporádicas. Este afastamento das pessoas faz com que as cuidadoras busquem alternativas para o seu próprio suporte emocional que substituem o diálogo com as pessoas, tais como: chorar, rezar ou isolar-se.

Nesse sentido, MENDES (1995) considera que fatores psico-sociais interferem na forma dos sentimentos dos cuidadores serem objetivados no cotidiano do cuidador e do idoso, sendo comum à busca de valores religiosos como suporte para a aceitação deste cotidiano e dos sentimentos que afloram.

Os colaboradores manifestaram, ainda, que as condições do idoso são fatores preponderantes na realização de atividades extra-domiciliares. Muitas vezes, para desenvolverem ações voltadas ao lazer, como sair à noite, ou visitar amigos, há necessidade do idoso estar bem, caso contrário, a atenção precisa estar constantemente voltada a este, e o cuidador tem que readequar seus planos.

"Às vezes eu não realizo tudo que quero realizar. Às vezes quero sair à noite e não dá, porque tenho que pensar nela, então (...). Tudo depende de como ela está no dia, como ela levanta. Se está bem, ela pode ficar um pouco mais sozinha, senão não dá pra deixar. Tudo depende de como ela está". (Bat girl)

"Então eu digo, às vezes eu tenho vontade de sair, ir numa tia minha, mas não posso, num domingo, ir lá almoçar, mas não posso fazer o que quero, tenho que ficar cuidando da "vó", ela não pode caminhar muito, então eu fico e é assim". (Mulher gato)
Cuidar de uma pessoa dependente faz com que o estilo de vida do cuidador seja modificado em função das necessidades do outro. Independente do fato do cuidador ser uma pessoa jovem ou idosa, suas atividades de recreação e convívio social acabam sendo alteradas e dando a este a sensação de não ter autonomia para gerenciar a própria vida e ter de viver em torno do outro. O indivíduo que necessita dos cuidados, por sua vez, "cobra" a presença do cuidador e nem sempre reage favoravelmente às ausências.

Como bem explicita MENDES (1995), "a falta de liberdade e os momentos solitários vivenciados pelos cuidadores fazem com que o cuidador e o idoso se lancem numa relação de busca, querendo (re)montar, (re)fazer, (re)estabilizar uma vida cotidiana nos moldes anteriores, o que já não é mais possível pela demanda dos cuidados e pela dependência do idoso para com o cuidador". O processo de reconstrução da vida do cuidador é conflitante, exige tempo para desenhar um novo cotidiano, novas articulações, novos personagens, novas identidades que nascem de uma descontinuidade, mas mantém-se articuladas pela história de cada um (MENDES, 1995).

Em meio à solidão de ficar inserida somente no meio domiciliar e não ter liberdade para realizar o que gosta, os participantes deste estudo apontaram que, mesmo com a preocupação de cuidar do idoso doente e isto ser um fator gerador de dificuldades no enfrentamento pessoal, procuram reorganizar suas atividades de rotina e de vida para se sentirem, além de úteis, felizes consigo mesmo.

"E agora eu também então estou indo na ginástica ali, de quarta e sexta, é às duas horas e demora uma hora só. É tão pertinho, só que daí eu tenho que deixar ele fechado, ele fica sozinho, às vezes chega gente, não tem nem quem abra a porta, daí ficam batendo, é meio difícil, mas (...)". (Sherra)

"Agora eu estou mais assim, porque ele melhorou, assim mais feliz, ele melhorou, posso sair, vou no baile dos velhos, eu já tava com as pernas meio 
CATTANI, Roceli Brum; GIRARDON-PERLINI, Nara Marilene Oliveira - Cuidar do idoso doente no 268 domicílio na voz de cuidadores familiares. Revista Eletrônica de Enfermagem, v. 06, n. 02, p. 254-271, 2004. Disponível em www.fen.ufg.br

duras de não treinar as pernas, e agora dá pra eu ir, assim, às vezes". (Shena)

Diante da tentativa de readequação de suas vidas, os cuidadores principais ainda enfrentam dificuldades, pois na ausência de cuidadores secundários, muitas vezes, o idoso acaba por ficar sozinho no domicílio, enquanto realiza atividades fora de casa, situação esta que gera preocupação ao cuidador.

Podemos deduzir que, com o passar do tempo, o cuidador pode redefinir e redesenhar seu papel em relação às tarefas do cotidiano e do cuidado, que mesmo sendo conturbado, permite a ele vislumbrar opções de lazer e descontração. Para não adoecer, é importante que o cuidador perceba que está vivo, que não está doente e precisa continuar a sua vida da melhor forma possível.

A necessidade de mostrar ao cuidador a importância do desenvolvimento de atividades físicas e de lazer, de dedicar um tempo a si, para que possa manter sua saúde física e mental, foi apontado por PAVARINI et al. (2001). Esta necessidade está relacionada ao mal - estar e a frustração gerada pelas dificuldades para auto-cuidado, geralmente por falta de tempo, no caso dos cuidadores que, envolvidos no cuidado, muitas vezes, esquecem da sua própria vida. Por outro lado, os cuidadores referem que a reorganização das atividades, a fim de se distraírem, acontece, mais facilmente, quando o idoso melhora seu estado clínico, de debilidade e dependência.

Em uma reflexão mais abrangente e mais profunda, MENDES (1995), mostrou em sua pesquisa que o dia-a-dia do cuidador é radicalmente modificado pela doença. De acordo com esta pesquisadora, na relação de cuidar e ser cuidado, velhas relações pessoais são redefinidas, novas atividades, tanto de rotina como de vida e relações psico - sociais são introduzidas no seu cotidiano, e de certa forma, a doença põe em suspensão a vida cotidiana da família. Uma nova vida cotidiana se instala aos poucos reitroduzindo algo do velho cotidiano, no novo.

\section{CONSIDERAÇÕES FINAIS}

A partir de relatos da vida privada de alguns indivíduos, que narram fragmentos de seus cotidianos e deixam-nos conhecer os motivos pelos quais tornaram-se cuidadores, seus sentimentos e a realidade que vivenciam ao cuidar de um familiar idoso e dependente no domicílio, pudemos apreender um pouco do processo que envolve o cuidar e refletir sobre esta realidade, muitas vezes, ignorada pela própria sociedade e, de certa forma, afastada do cerne das discussões familiares e do cotidiano das atividades dos profissionais da saúde.

Ao analisarmos a interação cuidador idoso doente, entendemos que o processo de tornar-se cuidador se dá de diferentes formas, de acordo com as características e dos valores que constituem os elos de cada família. A obrigação e o dever embutidos no compromisso do matrimônio, unidos talvez, por uma regra de ação moral determinada ou pelo expressivo traço cultural existente hoje em nossa sociedade, na qual a mulher é que detém o papel de cuidadora, embora 0 homem esteja se revelando neste processo, pode representar fatores que predispõem o cuidador a tornar-se como tal.

Podemos evidenciar também, que existe um componente afetivo que conduz a atividade do cuidar, contribuindo para que um cônjuge cuide do outro, pois sentimentos de carinho, amor e ternura, apresentam-se para os cuidadores como fatores importantes e influenciadores na escolha de tal função.

Nesse sentido, também aparecem os filhos como cuidadores principais, quando o cônjuge não pode cuidar, por motivos de doença física e mental ou quando um ou outro é falecido. Este sentimento de afeto em relação ao idoso transcende também a outros familiares além dos filhos, pois a relação de parentesco faz com que outros cuidadores potenciais como os (as) netos (as) e as noras se deflagrem no processo de cuidar.

Sendo esposa ou esposo, filho (a), pai, mãe, neta (o) ou sogra (o), percebemos que a relação de parentesco influencia na escolha de quem cuida do idoso doente, bem como os laços afetivos entre os familiares. Quanto 
CATTANI, Roceli Brum; GIRARDON-PERLINI, Nara Marilene Oliveira - Cuidar do idoso doente no 269 domicílio na voz de cuidadores familiares. Revista Eletrônica de Enfermagem, v. 06, n. 02, p. 254-271, 2004. Disponível em www.fen.ufg.br

mais estreita for a relação parenteral, mais chance tem o indivíduo de vir a ser o responsável pelo cuidado.

Em meio à realização dos cuidados surgem, no decorrer do cotidiano, sentimentos muitas vezes ambíguos por parte do cuidador, que estão relacionados à evolução da doença e ao tipo de dependência apresentado pelo familiar que está sendo cuidado. Para desempenhar tal tarefa é necessário, na ótica dos cuidadores, ter ou desenvolver algumas características que possibilitem enfrentar o cuidar de forma objetiva e/ou subjetiva.

Assim, "agüentar" cuidar do idoso e se "conformar" com a situação, que muitas vezes lhes foi imposta ou gerada pela necessidade do idoso ter um cuidador, é importante no decorrer do processo, pois dificilmente haverá mudança na condição de quem está cuidando. O cotidiano do cuidado, pode de certa forma, produzir situações de conflito entre quem cuida, quem é cuidado e os demais integrantes da família, mas dificilmente altera esta condição. Tal fato faz o cuidador familiar sentir-se impotente diante da situação, percebendo-a como imutável e, de certa forma, contribuindo para que se resigne às circunstâncias.

Todavia o cuidar de um idoso doente no domicílio também pode estar revestido por sentimentos de gratidão e carinho, como possibilidade concreta de expressar a o reconhecimento por cuidados e atenção recebidos por parte desta pessoa em outras ocasiões. Nesta circunstância, o cuidado e as interações advindas destas trocas permitem que ambas as partes tornem-se cúmplices, revisando relações, redesenhando e fortalecendo seus novos e velhos papéis.

Podemos deduzir que com o passar do tempo o cuidador, em algumas situações,vai se adaptando a sua vida e seu papel em relação às tarefas do cotidiano e do cuidado, que mesmo enfrentando dificuldades e momentos conturbados nesse processo, se permite de uma forma ou de outra, vislumbrar opções de lazer e descontração, reintroduzindo em seu cotidiano, aos poucos, algo que lhe permita retomar a atenção para consigo mesmo.
Percebemos que o cuidado desempenhado pelo cuidador familiar ao idoso doente e dependente no âmbito domiciliar ainda compreende muitos "mistérios" a serem desvendados e compreendidos pela enfermagem. Nesse sentido, a enfermeira e sua equipe de saúde, inserida no campo da saúde coletiva ou hospitalar, pode proporcionar suporte às famílias que têm em seus domicílios idosos doentes, pois, através do trabalho que é desenvolvido por intermédio das visitas domiciliárias às famílias, podem ser evidenciadas as necessidades que os cuidadores enfrentam durante o processo de cuidar e assim colaborar na assistência tanto ao cuidador, que muitas vezes, desconhece o cuidado no domicílio, bem como ao idoso que necessita de atenção.

Vários estudos têm sido realizados nos últimos anos mostrando o papel desempenhado pelos cuidadores familiares na sociedade, constituindo-se numa rede autônoma de atendimento a situações que envolvem saúde, doença e cuidado, sem o devido reconheciemento e apoio por parte dos serviços de saúde oficiais. Os cuidadores familiares muitas vezes desconhecem que poderiam recorrer aos profissionais de saúde e aos serviços de saúde para buscar apoio, orientações e ajuda no seu fazer. Algumas ações implantadas pelo sistema de saúde têm buscado, em seus princípios, fortalecer a contribuição família para a manutenção e melhora dos níveis de saúde de seus integrantes e, conseqüentemente, dos cuidados realizados nos domicílios às pessoas que apresentam algum tipo de dependência, todavia a implantação desta proposta na prática ainda carece efetivação.

Diante disso o exercício de competência da enfermagem, talvez seja vital para que, diante das dificuldades evidenciadas no cotidiano dos cuidadores, possam se sentir assistidos e não solitários enquanto cuidam, pois informação e acompanhamento dos cuidadores domiciliários, pode influenciar no desenvolvimento das tarefas desempenhadas no cuidado ao idoso doente.

Ao acompanhar o cuidador no domicílio, os profissionais da área da enfermagem 
CATTANI, Roceli Brum; GIRARDON-PERLINI, Nara Marilene Oliveira - Cuidar do idoso doente no 270 domicílio na voz de cuidadores familiares. Revista Eletrônica de Enfermagem, v. 06, n. 02, p. 254-271, 2004. Disponível em www.fen.ufg.br

dando auxílio, prestando uma assistência efetiva e, além disso, proporcionando a este, um acolhimento de forma digna ao serviço de saúde, podem colaborar para que o familiar em vez da inexperiência, possa desenvolver conhecimentos e habilidades para lidar com a demanda de cuidados que a doença do idoso exige, em meio ao cotidiano. Torna-se importante, também, salientar o apoio da enfermagem nesse processo, para que o cuidar não se torne desgastante, tendo o cuidador que "driblar" de forma cansativa os fatores geradores de sobrecarga. Também precisam sentir que cuidar não é viver na solidão, nem perder a liberdade, compreendendo que existe uma equipe de saúde colaborativa e envolvida nesse processo cuidador - família.

Talvez, a solução de continuidade ainda existente nesta relação de cuidado entre o cuidador e a enfermagem necessite de um envolvimento maior entre ambos, que possibilite o conhecer-se e vislumbrar as possibilidades do que ambos tem a oferecer em termos de necessidades e expectativas, para que assim ocorra uma melhor resolutividade nas ações voltadas ao idoso na esfera domiciliar.

Em suma, pensamos que o profissional enfermeiro e demais membros da equipe de enfermagem, como agentes transformadores no campo da saúde, devem estar atentos e comprometidos com a assistência domiciliária ao cuidador e ao idoso doente, pois através de uma assistência de qualidade e não somente da realização de visitas "rápidas" aos domicílios, podem perceber de uma forma mais ampla o processo saúde-doença, englobando os fatores psico-sociais de cada um, além de evidenciar os motivos que tornaram os cuidadores como tal e os sentimentos e necessidades destes enquanto cuidam, proporcionando assim, qualidade de vida aos cuidadores e também ao familiar doente.

Desse modo, proporcionar aos "superheróis", apoio e contentamento, para se sentirem valorizados e assisti-los de forma digna, torna-se importante de modo a fazêlos perceber que, não são meros cuidadores vivendo no anonimato, num domicílio qualquer, mas que existe uma gama de pessoas envolvidas nesse processo, dispostas e capazes de ajudá-los

\section{REFERÊNCIAS BIBLIOGRÁFICAS}

BALTES, M. M; SILVERBERG, S. A dinâmica de dependência - autonomia no curso de vida. In: NERI, A. L. Psicologia do Envelhecimento: temas selecionados na perspectiva do curso de vida. São Paulo: Papirus, 1995.

BRASIL. Lei 8.842, de 4 de janeiro de 1994. Dispõe sobre a Política Nacional do Idoso, cria o Conselho Nacional do Idoso e dá outras providências. In: Política Nacional do Idoso. Brasília, 1998.

BRASIL. Ministério da Saúde. Conselho Nacional de Saúde. Resolução 196 de 10 de outubro de 1996. Diretrizes e normas regulamentadoras da pesquisa envolvendo seres humanos. Brasília, 1996.

BRITO, F. C.; RAMOS, L. R. Serviços de atenção à saúde do idoso. In: PAPALÉO, N. M. Gerontologia. São Paulo: Atheneu, 1996.

CALDAS, C. P. (org). A saúde do idoso: a arte de cuidar. Rio de Janeiro: UERJ, 1998.

CHIZZOTTI, A. Pesquisa em Ciência Humana e Sociedade. São Paulo: Cortez, 1991.

DELGADO, J. A. A família vivenciando situações de saúde-doença: um conhecimento em construção. In: ELSEN, I.; MARCON, S. S.; SANTOS, M. R. (orgs). O viver em família e sua interface com a saúde e a doença.

Maringá: Eduem, 2002.

DIOGO, M. J. D' E.; DUARTE, Y. A. O. Cuidados em domicílio: conceitos e práticas. In: FREITAS E. V. et al. Tratado de Geriatria e Gerontologia. Rio de janeiro: Guanabara Koogan, 2002.

ELSEN, I.; MARCON, S. S.; SANTOS, M. R. (orgs). O viver em família e sua interface com a saúde e a doença. Maringá: Eduem, 2002.

FERREIRA, A. B. H. Novo Aurélio Século $X X I$ : o dicionário da língua portuguesa. $3^{a}$ ed. Rio de Janeiro: Nova Fronteira, 1999.

FREITAS, E. V. et al. Tratado de Geriatria e Gerontologia. Rio de janeiro: Guanabara Koogan, 2002. 
CATTANI, Roceli Brum; GIRARDON-PERLINI, Nara Marilene Oliveira - Cuidar do idoso doente no 271 domicílio na voz de cuidadores familiares. Revista Eletrônica de Enfermagem, v. 06, n. 02, p. 254-271, 2004. Disponível em www.fen.ufg.br

GIL, A. C. Métodos e técnicas de pesquisa social. $4^{a}$ ed. São Paulo: Atlas, 1995.

GIRARDON-PERLINI, N. M. O. Cuidar de pessoa incapacitada por acidente vascular cerebral no domicílio: o fazer do cuidador familiar. Coleção trabalhos acadêmicocientíficos. Série dissertações de mestrado, 19. Ijuí: UNIJUİ, 2001.

KARSCH, U. M. S. (org). Envelhecimento com dependência: revelando cuidadores. São Paulo: EDUC, 1998.

LEITE, R. C. B. O. O idoso dependente em domicílio. 1995. Bahia, 1995. Dissertação (Mestrado). Faculdade de Enfermagem, Universidade Federal da Bahia.

MENDES, P. M. T. Cuidadores: heróis anônimos do cotidiano. São Paulo, 1995. Dissertação (Mestrado). Pós- Graduação em Serviço Social, Pontifícia Universidade Católica de São Paulo.

MENEZES, A. K. Cuidados à pessoa idosa: reflexões gerais. In: Sociedade Brasileira de Geriatria e Gerontologia - RJ. Caminhos do Envelhecer. Rio de Janeiro: Revinter, 1994.

MINAYO, M. C. S. O desafio do conhecimento: pesquisa qualitativa em saúde. $2^{\mathrm{a}}$ ed. São Paulo-Rio de Janeiro: HUCITEC, 1993.

MINAYO, M. C. S.; et al. Pesquisa Social: teoria, método e criatividade. $19^{\mathrm{a}}$ ed. Petrópolis: Vozes, 2001.

NERI, A. L. (org.) Bem-estar e estresse em familiares que cuidam de idosos fragilizados e de alta dependência. In: Qualidade de vida e idade madura. Campinas: Papirus, 1993.

PAVARINI, et al. De necesidades à intervenção: etapas na organização de um serviço de orientação para cuidadores de idosos. In: Seminário de Metodologia para Projetos de Extensão, IV, São Carlos, 2001, p.29-31.

SARTI, C. A. Família e individualidade: um problema moderno. Texto preparado para mesa redonda "Perspectivas de análise teórica da família", no Seminário A família contemporânea em debate. Instituto de Estudos Especiais da PUC de São Paulo. São Paulo, outubro de 1993 (mimeo).

SILVA, I. P. As relações de poder entre no cotidiano das mulheres cuidadoras. In: KARSCH, U. M. S. (org). Envelhecimento com dependência: revelando cuidadores. São Paulo: EDUC, 1995.

SOMMERHALDER, C.; NERI A. L. Avaliação subjetiva da tarefa de cuidar: ônus $\mathrm{e}$ benefícios percebidos por cuidadoras familiares de idosos de alta dependência. In: NERI, A. L. (org). Cuidar de idosos no contexto da família: questões psicológicas sociais. Campinas: Átomo Alínea, 2002.

VICTORA, C. G.; KNAUTH, D. R.; HASSEN, M. N. A. Pesquisa qualitativa em saúde: uma introdução ao tema. Porto Alegre: Tomo Editorial, 2000.

Texto recebido em 09/08/2004.

Publicação aprovada em 31/08/2004 